\title{
An Elementary Proof of Fermat's Last Theorem
}

\author{
John Sherrill \\ Library, South Plains College, Plainview TX, USA
}

Email address:

jsherrill@southplainscollege.edu

\section{To cite this article:}

John Sherrill. An Elementary Proof of Fermat's Last Theorem. Mathematics Letters. Vol. 3, No. 5, 2017, pp. 52-52. doi: $10.11648 /$ j.ml.20170305.12

Received: July 26, 2017; Accepted: August 22, 2017; Published: October 10, 2017

Abstract: This paper presents an elementary proof of Fermat's Last Theorem using mathematics that was available to Fermat. It shows that equation $a^{n}=b^{n}+c^{n}$ has no solution in natural numbers if a is prime or a power of a prime then uses that result to present a general proof.

Keywords: Fermat's Last Theorem, Pierre de Fermat

\section{Introduction}

Fermat's Last Theorem was the conjecture that equation

$$
\mathrm{a}^{\mathrm{n}}=\mathrm{b}^{\mathrm{n}}+\mathrm{c}^{\mathrm{n}}
$$

has no solution in natural numbers $a, b, c$, and $n$ if $n>2$. I will first present a partial proof showing Equation 1 to have no solution in natural numbers if $a$ is prime or a power of a prime and then use that result to present a general proof.

\section{Partial Proof}

Fermat himself proved the case of $n=4$ and thereby proved all cases in which $\mathrm{n}$ is a multiple of 4 . Since all other integers greater than 2 are divisible by an odd prime, it is sufficient to assume that $\mathrm{n}$ is an odd prime. It can also be assumed that $\mathrm{a}, \mathrm{b}$, and $\mathrm{c}$ are relatively prime.

The relationships among $\mathrm{a}, \mathrm{b}$, and $\mathrm{c}$ are: $\mathrm{a}>\mathrm{b}, \mathrm{a}>\mathrm{c}$, and $(\mathrm{b}$ $+\mathrm{c}) / 2<\mathrm{a}<\mathrm{b}+\mathrm{c}<2 \mathrm{a}$. The identity

$$
\begin{aligned}
a^{\mathrm{n}}= & b^{\mathrm{n}}+\mathrm{c}^{\mathrm{n}} \\
= & \mathrm{b}^{\mathrm{n}}-(-\mathrm{c})^{\mathrm{n}} \\
& =(\mathrm{b}+\mathrm{c})\left[\mathrm{b}^{\mathrm{n}-1}+\mathrm{b}^{\mathrm{n}-2}(-\mathrm{c})+\ldots+\mathrm{b}(-\mathrm{c})^{\mathrm{n}-2}+(-\mathrm{c})^{\mathrm{n}-1}\right]
\end{aligned}
$$

shows that $\mathrm{b}+\mathrm{c}$ divides $\mathrm{a}^{\mathrm{n}}$. Since $\mathrm{b}+\mathrm{c}>\mathrm{a}$, there exists $\mathrm{a}$ natural number $y$ such that $b+c=a+y$. If $a$ is either prime or a power of a prime, there exist natural numbers $\mathrm{p}$ and $\mathrm{m}$, where $p$ is prime, such that $p^{m}=a, p^{m n}=b^{n}+c^{n}$, and $p^{m}+y$ divides $p^{\mathrm{mn}}$. Since $\mathrm{p}$ is the only prime divisor of $\mathrm{p}^{\mathrm{mn}}$, any divisor of the form $\mathrm{p}^{\mathrm{m}}+\mathrm{y}$ must equal $\mathrm{p}^{\mathrm{k}}$, where the natural number $\mathrm{m}<\mathrm{k} \leq \mathrm{mn}$. Thus $\mathrm{p}^{\mathrm{m}}+\mathrm{y}=\mathrm{p}^{\mathrm{k}}, \mathrm{y}=\mathrm{p}^{\mathrm{k}}-\mathrm{p}^{\mathrm{m}}=\mathrm{p}^{\mathrm{m}}\left(\mathrm{p}^{\mathrm{k}-\mathrm{m}}\right.$ $-1)$, and a divides $\mathrm{y}$. But that is a contradiction because $\mathrm{a}>$ $(a+y) / 2$ and $a>y$.

\section{General Proof}

Since $p^{m n} \neq b^{n}+c^{n}$, to prove Fermat's Last Theorem it remains to show that $\mathrm{p}^{\mathrm{mn}}$ is not equal to the sum of the nth powers of two rational numbers. For if $a^{n}=b^{n}+c^{n}$, there must exist a natural number $\mathrm{w}>1$ such that $\mathrm{p}^{\mathrm{m}} \mathrm{w}=\mathrm{a}, \mathrm{p}^{\mathrm{mn}} \mathrm{w}^{\mathrm{n}}=$ $b^{n}+c^{n}$, and $p^{m n}=b^{n} / w^{n}+c^{n} / w^{n}$.

Since $p^{m n} \neq b^{n}+c^{n}$, there must exist a natural number $t>1$ such that $p^{m n}=b^{n}+t$ and $t^{1 / n}$ is irrational. If there is a prime number $\mathrm{p}^{\prime}<\mathrm{p}$ such that $\mathrm{p}^{\text {'mn }}=\mathrm{b}^{\mathrm{n}} / \mathrm{w}^{\mathrm{n}}+\mathrm{t} / \mathrm{w}^{\mathrm{n}}$, then $\mathrm{p}^{\text {,mn }}$ is not equal to the sum of the nth powers of two rational numbers because $\left(\mathrm{t} / \mathrm{w}^{\mathrm{n}}\right)^{1 / \mathrm{n}}$ is irrational.

Consequently Equation 1 has no solution in natural numbers if $\mathrm{n}>2$.

\section{Acknowledgements}

Partial proof reprinted, with minor revision, with permission of Applied Probability Trust. Copyright (C) Applied Probability Trust 1994.

\section{References}

[1] Sherrill, J. (1994). A Partial Proof of Fermat's Last Theorem, Mathematical Spectrum 27(1), 12. 